\title{
Spectrum of Chest Computerised Tomography (CT) findings of Covid 19 in Indian Population
}

Date of Receiving: 12/01/2021

Date of Peer Review: 5/02/2021

Date of Acceptance: 16/02/2021

DOI:10.47799/pimr.0901.09

Boini Shravya ${ }^{1}$, Vikas Chennamaneni $^{2}$, Vamshi Kiran Diddy ${ }^{3}$, Momin Sayed Kashif ${ }^{4}$

1. Post Graduate 2nd Year, Department of Radio diagnosis, Prathima institute of medical sciences, Nagnur road, karimnagar

2. Professor, Department of Radiodiagnosis, Prathima institute of medical sciences, Nagnur road, karimnagar

3. Assistant Professor, Department of Radiodiagnosis, Prathima institute of medical sciences,nagnur road, karimnagar

4. Associate Professor, Department of Community Medicine, Prathima institute of medical sciences

Corresponding Author: Dr. Vikas Chennamaneni, Professor, Department of Radiodiagnosis, Prathima institute of medical sciences, Nagnur road, karimnagar

\section{ABSTRACT:}

Background: To analyze the chest computed tomography (CT) features in patients with coronavirus disease 2019 (COVID-19) pneumonia.

Methods: This was a prospective descriptive study comprising 202 consecutive reverse transcriptase polymerase chain reaction (RT-PCR) positive patients who underwent $C T$ chest. For 25 patients, follow-up CT scans were obtained. The CT images were evaluated for the number, type and distribution of the opacity, and CT severity scoring was done

Results: Among the total study cohort of 202 patients, 152 were males and 50 were females .From July 07, 2020, to september07, 2020, totally 202 laboratory-confirmed patients with COVID-19 underwent chest CT. For 25 patients, follow-up CT scans were obtained. The CT images were evaluated for the number, type and distribution of the opacity, and the affected lung lobes. Furthermore, the initial CT scan and the follow-up CT scans were compared. Results were patients $(98.5 \%)$ had two or more opacities in the lung and $3(1.5 \%)$ patients has negative chest CT. 183 (90.6\%) patients had only ground-glass opacities; 13 patients $(6.4 \%)$ had ground-glass and consolidative opacities; and 3 patients $(1.5 \%)$ had only consolidation. A total 192 of patients (96.5\%) showed two or more lobes involved. The opacities tended to be both in peripheral and central 7 (3.5\%) or purely peripheral distribution 192 (96.5\%). 177 patients (88.9\%) had the lower lobe involved.8 patients showed complete resolution of lung findings.
Conclusion:

In this study population, the typical CT features of COVID 19 pneumonia are ground glass opacity with or without consolidation, which is patchy and peripheral, predominantly in lower lobes.

Introduction

Since December 2019, dozens of unexplained pneumonia cases have occurred in Wuhan City, Hubei Province, China, and there are few reports suggesting that the outbreak is related to exposure at the Wuhan South China Seafood Market. In subsequent months, pneumonia has spread in China and globally. Studies have shown that a new betacoronavirus known as COVID-19 (formerly known as 2019-nCoV). COVID19 was listed as a public health emergency by the World Health Organization (WHO) on January 30, 2020

Coronaviruses are enveloped nonsegmented positive sense RNA viruses belonging to the family Coronaviridae and the order Nidovirales and broadly distributed in humans and other mammals (1).The most common CT manifestations are bilateral, peripheral/sub pleural, posterior GGOs with or without consolidations with a lower lobe predominance (2) The aim of the present study was to report the chest CT imaging manifestations of SARS-CoV-2 infection in Karimnagar, India. 


\section{MATERIAL AND METHODS}

\subsection{Patient cohort and study design:}

This was a cross sectional study from July 072020 to September 072020 conducted in Karimnagar, India, 202 consecutive symptomatic patients were subjected to chest CT after obtaining nasopharyngeal swab for RT-PCR

\subsubsection{Inclusion criteria:}

Patients with symptoms such as fever, cough, fatigue, sore throat and/or dyspnoea with RT-PCR confirmed SARS-CoV2 infection.

\subsubsection{Exclusion criteria:}

Non consenting patients

\subsection{CT acquisition protocol:}

Non-contrast chest $\mathrm{CT}$ was performed with the following parameters: tube voltage 100-120 kVp, tube current 90-130 $\mathrm{mA}$ s.The $\mathrm{CT}$ images were acquired in a single inspiratory breath-hold. Images were reconstructed using increment of $0.7 \mathrm{~mm}$ into $1 \mathrm{~mm}$ thick slices. Decontamination of the CT suite was performed using $70 \%$ ethanol or $0.1 \%$ sodium hypochlorite. After each CT examination, passive air exchange was allowed for $60 \mathrm{sec}$.

\subsection{Image analysis:}

All the cases were reviewed by a senior radiologist. The readers assessed the following features: presence or absence of pulmonary opacities; location; type of opacities and the extent of opacities. The location of lesions was specified with regards to involvement of one lung (right, left) or both the lungs. The number of lobes involved was determined. Zonal distribution of the opacities was classified as central (defined as the inner two-third of the lung tissue) and peripheral (defined as outer one-third of the lung). Lung lesions were categorized using Fleischner society glossary of terms for thoracic imaging. GGO (ground glass opacity) was defined as an increase in the density of lung with non-obscuration of bronchial and vascular structures, whereas consolidation was defined as increased density of lung tissue through which vascular and bronchial structures were not visible. Furthermore, the readers also evaluated presence of associated airway, vascular, pleural and mediastinal abnormalities. Each of the five lung lobes was visually scored on a scale of 0 to 5 ,

Table 1:

DEMOGRAPHICS

GROUP STATISTICS

\begin{tabular}{|c|c|c|c|c|}
\hline & SEX & Number & MEAN AGE & $\begin{array}{c}\text { STANDARD } \\
\text { DEVIATION }\end{array}$ \\
\hline \multirow{2}{*}{ AGE } & MALE & 152 & 47.32 & 12.907 \\
& FEMALE & 50 & 51.52 & 14.692 \\
\hline
\end{tabular}

with 0 indicating no involvement and 5 indicating more than $75 \%$ involvement. The total CT score was determined as the sum of lung involvement, ranging from 0 (no involvement) to 25 (maximum involvement).

\section{RESULTS}

\subsection{Demographics:}

Among the total study cohort of 202 patients, 152 were males and 50 were females with mean age of $47.32 \pm 12$.9years in males and 51.52+14.6 in female (range 24-71 years). In 180 $(90 \%)$ cases a history of close contact with an infected patient or a history of travel to a high risk zone within or outside the country was forthcoming. Patient demographics are summarized in Table 1.

\subsection{Chest CT findings:}

Lung parenchyma abnormalities were observed in 199(98.5\%) cases, whereas 3(1.5 \%) RT-PCR positive cases had a normal chest CT. Among the patients with abnormal CT findings, bilateral lung involvement was the commonest, observed in 192(96.5\%). Multiple lobe involvement was seen more frequently. 164(81.2\%) had involvement of all the 5 lobes whereas two lobe and single lobe involvement was seen in 7 (3.5\%) each. In terms of axial distribution, peripheral distribution was the commonest, seen in 199(98.5 \%) cases among which 192 (96.5\%) had only peripheral distribution whereas as $7(3.5 \%)$ had both peripheral and central distribution. Chest CT imaging manifestations are given in Table 2. With regards to the type of opacity, GGO was the dominant abnormality, found in all $199(98.5 \%)$ cases. GGO with interlobular septal thickening and intralobular lines, producing crazy paving pattern was seen in $183(90.6 \%)$ and GGO mixed with consolidation was noted in $13(6.4 \%$ ) (Figs. 2 and 3). Pure consolidation was noted in $3(1.5 \%)$. CT severity score was calculated and a mean score of 8.9 with SD of 4.428 was obtained. A small number of cases showed atoll or reverse halo sign $2(1.1 \%)$ cases, airway secretions in $5(2.5 \%)$ cases, cysts $2(1 \%)$ cases, pleural effusions $3(1.5 \%)$ cases, pneumothorax in $1(0.5 \%)$ case and pneumomediastinum in $1(0.5 \%)$ case. (Fig. 3 ). None of the patients showed halo sign or pericardial effusion or mediastinal lymphadenopathy. Follow-up was done for around 25 patients of which 8 patients showed complete resolution of lung opacities.

CT severity scoring was summarized in Table 3 . 
Independent Samples Test

\begin{tabular}{|c|c|c|c|}
\hline \multirow{2}{*}{} & \multicolumn{3}{|c|}{ t-test for Equality of Means } \\
\cline { 3 - 5 } & $\mathrm{t}$ & $\mathrm{df}$ & Sig. (2-taild) \\
\hline AGE $\quad$ Equl variance assumed & -1.929 & 200 & .055 \\
\hline
\end{tabular}

Table 2: CHEST CT IMAGING MANIFESTATIONS

\begin{tabular}{|c|c|c|}
\hline & & TOTAL \\
\hline BILATERAL OR UNILATERAL & $\begin{array}{l}\text { BILATERAL } \\
\text { UNILATERAL }\end{array}$ & $\begin{array}{c}192(96.5 \%) \\
7(3.5 \%)\end{array}$ \\
\hline LOBAR INVOLVEMENT & $\begin{array}{c}\text { LLL } \\
\text { LUL } \\
\text { RLL } \\
\text { RML } \\
\text { RUL } \\
\text { TOTAL }\end{array}$ & $\begin{array}{c}42(21.1 \%) \\
10(5 \%) \\
135(67.8 \%) \\
1(0.5 \%) \\
11(5.5 \%) \\
199(100 \%)\end{array}$ \\
\hline NO OF LOBES & $\begin{array}{l}0 \\
1 \\
2 \\
3 \\
4 \\
5\end{array}$ & $\begin{array}{c}3(1.5 \%) \\
7(3.5 \%) \\
1(0.5 \%) \\
7(3.5 \%) \\
20(9.9 \%) \\
164(81.2 \%)\end{array}$ \\
\hline $\begin{array}{l}\text { NO OF LOBES } \\
\text { TOTAL }\end{array}$ & $\begin{array}{c}\text { ONE LOBE } \\
\text { MORE THAN ONE LOBE }\end{array}$ & $\begin{array}{c}7(3.5 \%) \\
192(95 \%) \\
199(100 \%)\end{array}$ \\
\hline DISTRIBUTION & $\begin{array}{c}\text { CENTRAL+PERIPHERAL } \\
\text { PERIPHERAL } \\
\text { TOTAL }\end{array}$ & $\begin{array}{c}7(3.5 \%) \\
192(96.5 \%) \\
199(100 \%)\end{array}$ \\
\hline FINDING & $\begin{array}{c}\text { ABSENCE OF ANY FINDINGS } \\
\text { CONSOLIDATION } \\
\text { GGO } \\
\text { GGO+CONSOLIDATION }\end{array}$ & $\begin{array}{c}3(0.5 \%) \\
3(0.5 \%) \\
183(90.6 \%) \\
13(6.4 \%)\end{array}$ \\
\hline ADDITIONAL FINDINGS & $\begin{array}{c}\text { CRAZY PAVING } \\
\text { AIRWAY SECRETIONS } \\
\text { ATOLL SIGN } \\
\text { CYSTS } \\
\text { EMPHYSEMATOUS CHANGES } \\
\text { PLEURAL EFFUSION } \\
\text { PNEUMOMEDIASTINUM } \\
\text { PNEUMOTHORAX }\end{array}$ & $\begin{array}{c}174(98.9 \%) \\
5(2.5 \%) \\
2((1 \%) \\
2(1 \%) \\
2(1 \%) \\
3(1.5 \%) \\
1(0.5 \%) \\
1(0.5 \%)\end{array}$ \\
\hline
\end{tabular}


Note: RUL: Right upper lobe, RML: Right middle lobe, RLL:

Right lower lobe, LUL: Left upper lobe, LLL: Left Lower Lobe, GGO: Ground-glass opacities

TABLE 3: CT SEVERITY SCORING:

\section{CT SCORE}

\begin{tabular}{|c|c|c|c|c|}
\hline & SEX & Number & MEAN & $\begin{array}{c}\text { STANDARD } \\
\text { DEVIATION }\end{array}$ \\
\hline \multirow{2}{*}{ CT SCORE } & MALE & 149 & 9.08 & 4.461 \\
& FEMALE & 50 & 8.42 & 4.333 \\
\hline
\end{tabular}

INDEPENDENT SAMPLES TEST

$T(D F=200)=-0.9, P=0.36$

\begin{tabular}{|c|c|c|c|c|}
\hline \multicolumn{3}{|c|}{ TOTAL } & STATISTIC & $\begin{array}{l}\text { STANDARD } \\
\text { ERROR }\end{array}$ \\
\hline CT SCORE & $\begin{array}{l}\text { MEAN } \\
\text { 95\% CONFIDENCE } \\
\text { INTERVAL FOR MEAN } \\
\text { 5\% TRIMMED MEAN } \\
\text { MEDIAN } \\
\text { VARIANCE } \\
\text { STANDARD. DEVIATION } \\
\text { MINIMUM } \\
\text { MAXIMUM } \\
\text { RANGE } \\
\text { INTERQUARTILE RANGE } \\
\text { SKEWNESS } \\
\text { KURTOSIS }\end{array}$ & $\begin{array}{l}\text { LOWER } \\
\text { BOUND } \\
\text { UPPER BOUND }\end{array}$ & $\begin{array}{c}8.91 \\
8.30 \\
\\
\\
\\
9.53 \\
8.76 \\
8.00 \\
19.604 \\
4.428 \\
0 \\
21 \\
21 \\
6 \\
.625 \\
-.112\end{array}$ & $\begin{array}{l}.172 \\
.343\end{array}$ \\
\hline
\end{tabular}

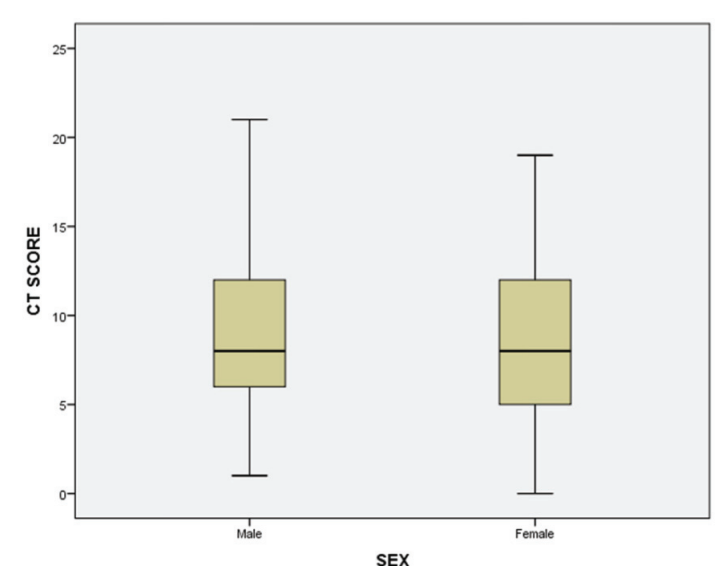

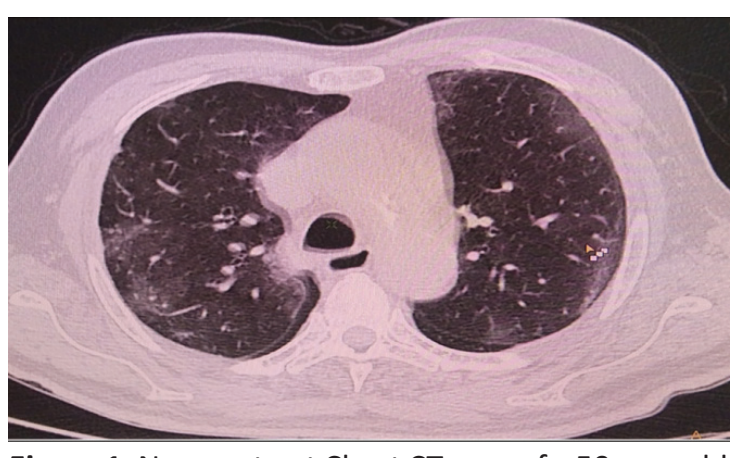

Figure 1: Non contrast Chest CT scan of a 50 year old man with confirmed Covid 19 pnuemonia.Few small peripheral patchy Ground Glass opacities were the only positive findings 


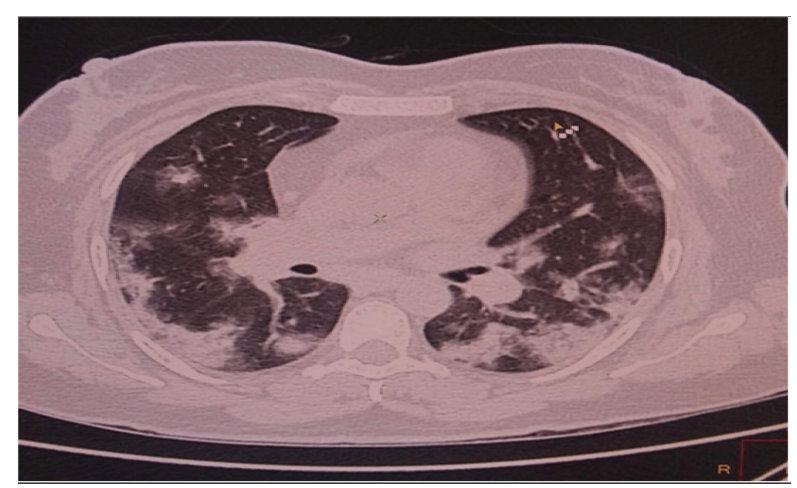

Figure 2: Non contrast Chest CT scan of a 28 year old man with confirmed Covid 19 Pneumonia. Multiple peripheral consolidation are shown bilaterally with patchy and segmental morphology

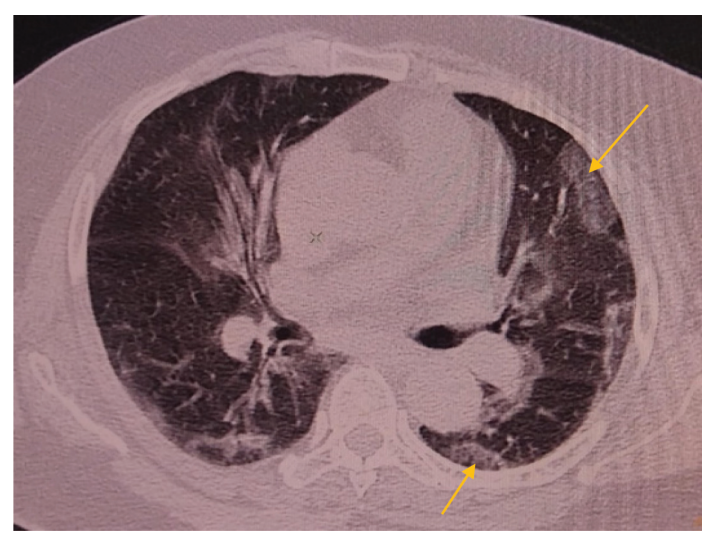

Figure 3: Non contrast Chest CT scan of a 62 year old women with confirmed Covid 19 Pneumonia Showing Patchy ground glass opacity with thickend inter lobular septa creating typical "crazy paving" apperance.

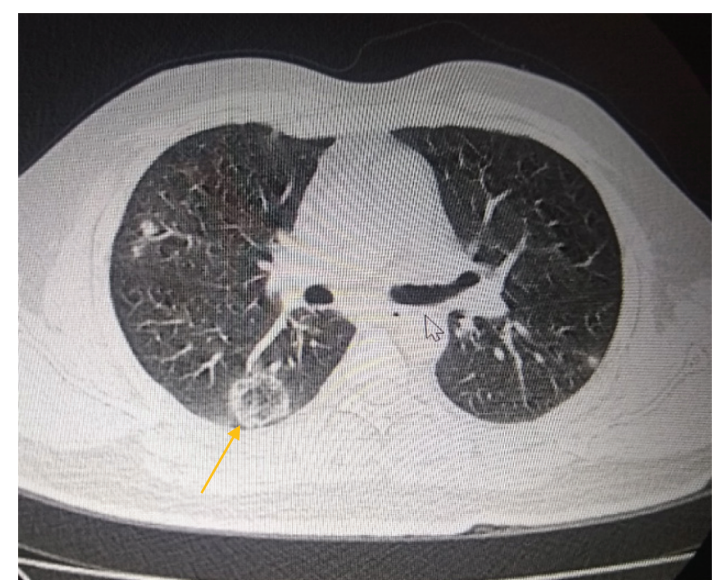

Figure 4: Non Contrast Chest CT scan of a 56 year old man with confirmed COVID 19 Pneumonia. Typical Reverse -halo sign or atoll sign

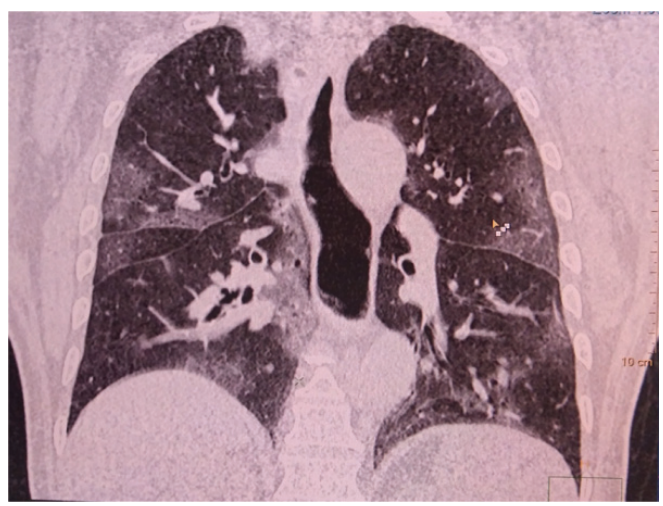

Figure 5: Non Contrast CT of 72 year old showing ground glass opacities with airway secretions

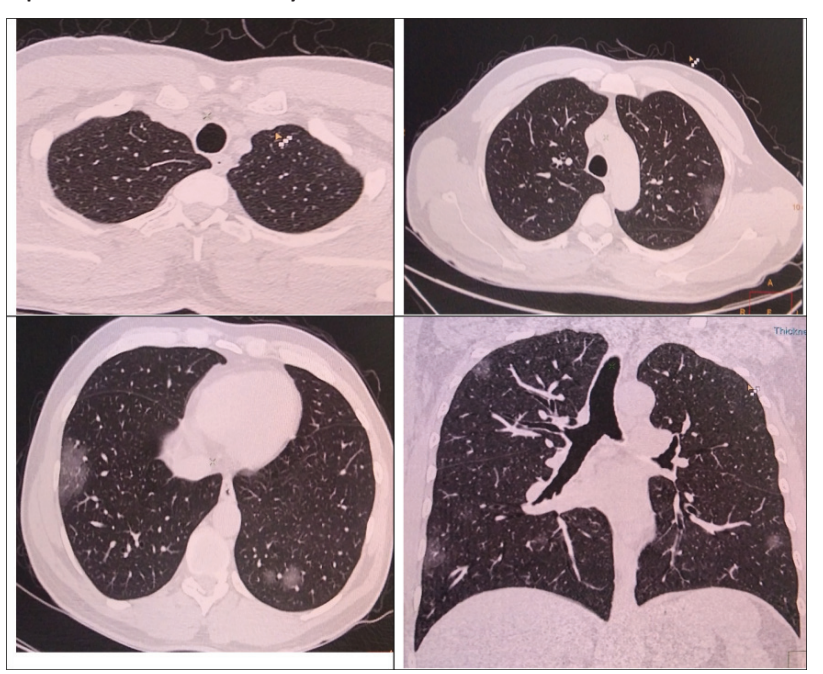

Figure 6: Non Contrast $\mathrm{Ct}$ of a 50 year old male came with history of fever and dry cough since 4 days and was in contact with a Covid positive patient

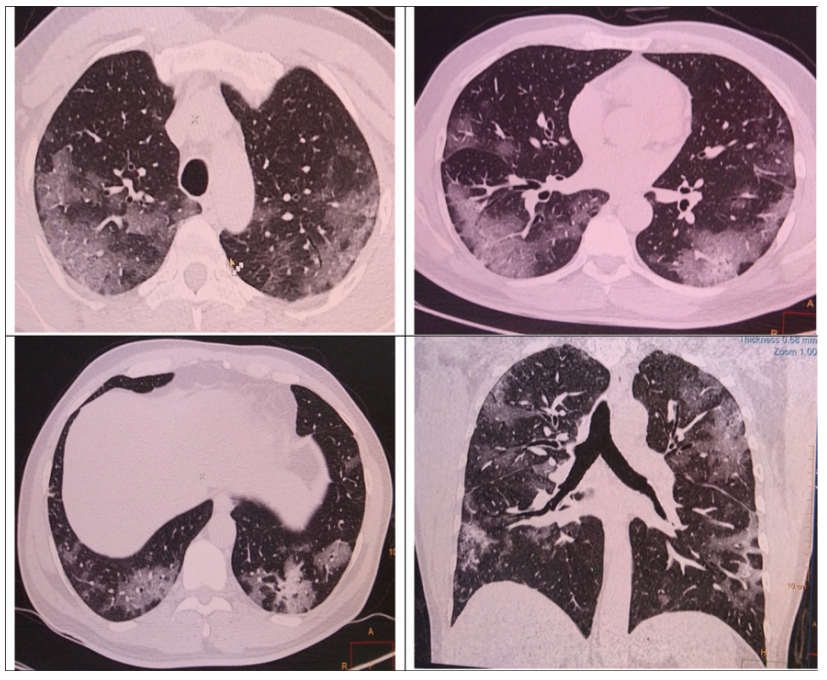

A follow up scan was done 15 days later for the above patient showed progression of lesion, showing bilateral, confluent ground glass opacities with pronounced peripheral and posterior distribution 


\section{DISCUSSION:}

COVID-19 pneumonia is a huge threat to public health because of to its high incidence and rapidly spreading nature. Hence, accurate and early recognition of the disease is crucial. Chest $\mathrm{CT}$ is a vital component in the diagnostic algorithm for patients suspected of having COVID-19 infection.

Although chest CT findings of COVID-19 pneumonia overlap with various other infectious or inflammatory lung processes, certain imaging characteristics and patterns exist in recently published data (4-7). Our study, is one of the few available investigations out of China, supports the previously identified typical CT features of COVID-19 pneumonia with the majority of cases demonstrating bilateral lung involvement in form of GGOs, predominantly peripheral distribution with lower lung zone predilection.

We recorded a positive CT in a high proportion (98.5\%) of patients with RT-PCR confirmed SARS-CoV-2in concurrence with studies from China, Korea and Europe which have reported lung parenchymal abnormalities in 61\%-100\% RT-PCR positive patients [8-10]

Caruso D et.al [10] reported pulmonary findings in 96.6 $\%$ of symptomatic cases on CT. Yu M et.al [11] reported a CT positivity rate of $100 \%$ in their study cohort

Ai T et.al [12] reported CT findings in 888 (88.7\%) among the total study population of 1014 COVID-19 patients. They further observed that 3\% RT-PCR positive cases with clinical symptoms had a normal CT scan.

Bao C et.al [13] in a meta-analysis of 13 studies with 2378 COVID19 cases found a pooled positive rate of $89.7 \%$ for CT. However study from India by pary et al showed positive findings in only in $34.7 \%$ patients contradicts our study [14]

Among the patients with lung parenchymal abnormalities on chest $\mathrm{CT}$, bilateral and multilobar distribution of pulmonary opacities with a peripheral predilection predominantly in lower lobes was commonly observed. Our results fairly corroborate the distribution and type of pulmonary opacities reported in COVID-19 pneumonia.

GGO in the form of pure GGO (90.6\%) or GGO admixed with consolidation ( $6 \%$ ) was the most dominant lung parenchymal abnormality encountered in all the cases. These findings are in concordance with the multiple studies summarized in the systematic review by Salehi et al.[16] wherein they found that GGO was present in $88 \%$ cases across 22 studies reported from various countries

Three asymptomatic patients had normal initial chest CT. All of them had a history of exposure to confirmed cases. This emphasizes the importance of the combination of chest CT and RT-PCR, and follow-up chest CT for timely diagnosis in clinically suspected in.Followup CT scans were done for 25 patients of which around 8 of them showed complete resolution of ground glass opacities.
Several limitations should be addressed. In our setting clinical and laboratory data were limited because of the urgency of the situation. Patient outcomes were not available at the time of this communication. There may have been a selection bias as imaging was performed in all symptomatic cases regardless of the severity of illness. The small size of study population is also a limitation.

In conclusion, the typical pattern of Corona virus Disease 2019 pneumonia on chest CT in Karimnagar, Telangana was characterized by the consistent presence of peripheral ground-glass opacities associated with multilobe involvement and bilateral distribution predominantly involving lower lobes.

\section{REFERENCES}

1. Wang K, Kang S, Tian R, Zhang X, Zhang X, Wang Y. Imaging manifestations and diagnostic value of chest CT of coronavirus disease 2019 (COVID-19) in the Xiaogan area. Clinical Radiology [Internet]. 2020 [cited 3 January 2021];75(5):341-347. Available from: https:// pubmed.ncbi.nlm.nih.gov/32216961/

2. Bernheim A, Mei X, Huang M, Yang Y, Fayad Z, Zhang N et al. Chest CT Findings in Coronavirus Disease-19 (COVID19): Relationship to Duration of Infection. Radiology [Internet]. 2020 [cited 3 January 2021];295(3):200463. Available from: https://pubs.rsna.org/doi/10.1148/ radiol.2020200463

3. Ojha V, Mani A, Pandey N, Sharma S, Kumar S. CT in coronavirus disease 2019 (COVID-19): a systematic review of chest CT findings in 4410 adult patients. European Radiology [Internet]. 2020 [cited 3 January 2021];30(11):6129-6138. Available from: https:// pubmed.ncbi.nlm.nih.gov/32474632/

4. Xie X, Zhong Z, Zhao W, Zheng C, Wang F, Liu J. Chest CT for Typical Coronavirus Disease 2019 (COVID-19) Pneumonia: Relationship to Negative RT-PCR Testing. Radiology [Internet]. 2020 [cited 3 January 2021];296(2):E41-E45. Available from: https://https:// pubs.rsna.org/doi/10.1148/radiol.2020200343

5. Chung $M$, Bernheim A, Mei X, Zhang N, Huang M, Zeng X et al. CT Imaging Features of 2019 Novel Coronavirus (2019-nCoV). Radiology [Internet]. 2020 [cited 3 January 2021];295(1):202-207. Available from: https://:https:// pubmed.ncbi.nlm.nih.gov/32017661/

6. Pan F, Ye T, Sun P, Gui S, Liang B, Li L et al. Time Course of Lung Changes at Chest CT during Recovery from Coronavirus Disease 2019 (COVID-19). Radiology [Internet]. 2020 [cited 3 January 2021];295(3):715-721. Available from: https://pubs.rsna.org/doi/10.1148/ radiol.2020200370 
7. Ye $Z$, Zhang $Y$, Wang $Y$, Huang $Z$, Song $B$. Chest $C T$ manifestations of new coronavirus disease 2019 (COVID19): a pictorial review. European Radiology [Internet]. 2020 [cited 3 January 2021];30(8):4381-4389. Available from: https://link.springer.com/article/10.1007/s00330020-06801-0

8. Li K, Fang Y, Li W, Pan C, Qin P, Zhong Y et al. CT image visual quantitative evaluation and clinical classification of coronavirus disease (COVID-19). European Radiology [Internet]. 2020 [cited 3 January 2021];30(8):4407-4416. Available from: https://link.springer.com/article/10.1007/ s00330-020-06817-6

9. Li Y, Xia L. Coronavirus Disease 2019 (COVID-19): Role of Chest CT in Diagnosis and Management. American Journal of Roentgenology [Internet]. 2020 [cited 3 January 2021];214(6):1280-1286. Available from: http://Y. Li, L. Xia, Coronavirus Disease 2019 (COVID-19): role of chest CT in diagnosis and management, Am. J. Roentgenol. (February) (2020) 1-7

10. Caruso D, Zerunian M, Polici M, Pucciarelli F, Polidori T, Rucci $C$ et al. Chest CT Features of COVID-19 in Rome, Italy. Radiology [Internet]. 2020 [cited 3 January 2021];296(2):E79-E85. Available from: https:// pubs.rsna.org/doi/10.1148/radiol.2020201237

11. Yu M, Xu D, Lan L, Tu M, Liao R, Cai S et al. Thin-Section Chest CT Imaging of COVID-19 Pneumonia: A Comparison Between Patients with Mild and Severe Disease. Radiology: Cardiothoracic Imaging [Internet]. 2020 [cited 3 January 2021];2(2):e200126. Available from: https:// pubs.rsna.org/doi/full/10.1148/ryct.2020200126

12. Ai T, Yang Z, Hou H, Zhan C, Chen C, Lv W et al. Correlation of Chest CT and RT-PCR Testing for Coronavirus Disease 2019 (COVID-19) in China: A Report of 1014 Cases. Radiology [Internet]. 2020 [cited 3 January 2021];296(2):E32-E40. Available from: https:// pubs.rsna.org/doi/10.1148/radiol.2020200642

13. Bao C, Liu X, Zhang H, Li Y, Liu J. Coronavirus Disease 2019 (COVID-19) CT Findings: A Systematic Review and Metaanalysis. Journal of the American College of Radiology [Internet]. 2020 [cited 3 January 2021];17(6):701-709. Available from: https://pubmed.ncbi.nlm.nih.gov/ 32283052/

14. Parry A, Wani A, Yaseen M, Dar K, Choh N, Khan N et al. Spectrum of chest computed tomographic (CT) findings in coronavirus disease-19 (COVID-19) patients in India. European Journal of Radiology [Internet]. 2020 [cited 3 January 2021];129:109147. Available from: Spectrum of chest computed tomographic (CT) findings in coronavirus disease-19 (COVID-19) patients in India Crossref DOI link: https://doi.org/10.1016/J.EJRAD.2020.109147
15. Salehi S, Abedi A, Balakrishnan S, Gholamrezanezhad A. Coronavirus Disease 2019 (COVID-19): A Systematic Review of Imaging Findings in 919 Patients. American Journal of Roentgenology [Internet]. 2020 [cited 3 January 2021];215(1):87-93. Available from: https:// pubmed.ncbi.nlm.nih.gov/32174129/

How to cite this article : Boini S,Chennamaneni V,Diddy V K,Kashif Momin . Spectrum of Chest Computerised Tomography (CT) findings of Covid 19 in Indian Population. Perspectives in Medical Research 2021; 9 (1): $43-49$ DOI:10.47799/pimr.0901.09

Sources of Support: Nil, Conflict of interest: None declared 